\title{
Exploring the Effect of Bicycle Infrastructure on Car Usage: A Case Study in Huhhot, China
}

\author{
Meiying Jian, ${ }^{1,2}$ Xiaojuan Li $\mathbb{D},,^{1,2}$ Jinxin Cao, ${ }^{1,2}$ and Zhenyu Liu $\mathbb{D}^{1,2}$ \\ ${ }^{1}$ Institute of Transportation, Inner Mongolia University, Huhhot 010070, China \\ ${ }^{2}$ Inner Mongolia Engineering Research Centre for Urban Transportation Data Science and Applications, Huhhot 010070, China
}

Correspondence should be addressed to Zhenyu Liu; 44855513@qq.com

Received 12 July 2020; Revised 29 December 2020; Accepted 20 January 2021; Published 12 February 2021

Academic Editor: Avinash Unnikrishnan

Copyright (C) 2021 Meiying Jian et al. This is an open access article distributed under the Creative Commons Attribution License, which permits unrestricted use, distribution, and reproduction in any medium, provided the original work is properly cited.

This study aimed to quantitatively investigate the effect of bicycle infrastructure on car usage. The mixed logit model with random coefficients was used to capture the differences in individuals' preferences. Based on data from a stated preference survey conducted in Huhhot, China, the estimated results showed that the mixed logit model provides better fitting than the standard logit model. Considerable variations were found in individuals' attitudes toward the use of cars and bicycles. Riding a bicycle is preferred by most individuals. Furthermore, based on the constraints for maintaining the effect on car usage equal, the equivalent change in parking fees for improvement in bicycle infrastructures was estimated. The results showed that the effect of a $100 \mathrm{~m}$ reduction in walking distance to bicycle stations on the probability of driving is the same as that of an approximately 2.00 yuan/h (US $0.30 \$ / \mathrm{h}$ ) increase in the parking fees, and the effect of providing bike lanes is in line with additional parking fees of approximately 3.00 yuan $/ \mathrm{h}$ (US $0.45 \$ / \mathrm{h}$ ). The findings of this study can be an important reference for decision makers to consider improvements in bicycle systems and rational allocation of infrastructure investment and road resources.

\section{Introduction}

With increased motorization, traffic congestion has become one of the major problems faced by many cities worldwide. Numerous measures and strategies have been adopted to mitigate the traffic congestion, such as prioritizing public transport, developing bicycle systems, and congestion pricing $[1,2]$. Among these, bicycle systems have been increasingly popular around the world since the last decade [3], due to various positive returns, such as reduction in traffic [4], fuel consumption, and harmful emissions [5-7], increases in public transportation service and economic outcome [8], and improvements in physical and mental health [9-13].

Many modern cities are committed to improving their bicycle systems. The most notable is the boom in bike-share programs across the globe [14-18]. By the end of 2017, approximately 230 million public bicycles had been launched by 77 bicycle-sharing companies worldwide [19]. It has been reported that these bicycles have served 17 billion trips [20]. However, the percentage of the modal shift from cars to bicycles is not high. It corresponds to approximately $0.3 \%-0.4 \%$ in Montreal, $0.46 \%-5.2 \%$ in Chinese cities, $2.1 \%$ in Washington, D.C., and $2 \%$ in London [21-24]. Numerous studies have been conducted to explore the factors that influence the usage of bicycles. The results indicated that safety concerns and convenience factors were key barriers to bike-share usage [21, 25-28].

Based on this, bicycle infrastructure has been built and improved in many cities [29, 30]. For instance, New York has made great efforts to expand bicycle lanes. On November 1,2019 , the City council passed an infrastructure investment plan to build 250 miles of protected bike lanes over the next five years [31]. This plan could make cycling more attractive and ensure the safety of cyclists. Although the introduction of bike-share programs in China is still in the early stages, a number of cities are aware of the importance of improving the cycling environment, including optimizing bike-share stations [32] and building bike lanes. Moreover, for the convenience of long-distance trips between different areas, 
dedicated bike lanes with a width of $6 \mathrm{~m}$ were constructed and opened in Beijing in May 2019. It was found that the accessibility of bike-share stations or bike lanes could significantly increase the use of bicycles [17, 33-39]. Nevertheless, it is not clear whether increased bicycle ridership would result in reduced car-travel. Furthermore, the improvement in the accessibility of bike-share stations and bike lanes should not only demand a large infrastructure investment but also occupy the limited road resources. Obviously, it is important and necessary to investigate the effect of bicycle infrastructure on car usage.

Therefore, the effect of bicycle infrastructure on car usage is explored in this study, Here, the bicycle infrastructure refers to bike lanes as well as bike-share stations. Although the dockless bike-sharing systems have no station, most cities provide physical or geofencing designated areas to park bicycles [40] (in the dockless bike-sharing system, bike stations refer to these parking areas). In order to reflect individuals' preferences, the data used in this study were collected from the residents accustomed to driving in Huhhot, China. Based on this, the mixed logit model was used to investigate the effect of bicycle infrastructure on the use of cars.

\section{Literature Review}

Many studies have investigated the effect of bicycle infrastructure. Most of them focused on its effect on bicycle user behaviour, about which there is a substantial amount of research. However, research on its impact on car usage is relatively limited.

With regard to the effect on riding frequency, a positive correlation was found between bicycle infrastructure and cycling frequency. For example, Dill and Carr [41] used the data from the 43 largest cities across the US and found that an increase of every mile in the length of bike lanes was linked to a $1 \%$ increase in bicycle ridership. A cross-country study also found that metropolitan investment in bicycle systems was positively associated with the level of bicycle usage [42]. Based on the trip database from Zhongshan in China, it was found that the length of bike lanes within the $1000 \mathrm{~m}$ buffer area around bike stations had a significant and positive impact on the use of public bicycles [3]. Obviously, the improvement in bicycle infrastructure enhances the attraction of cycling and ensures the safety of cyclists.

In addition to the effects on riding frequency, some studies have also investigated the relationship between bicycle infrastructure and the number of trips by car. Most of these studies focused on the impact of the introduction of the bike-sharing system itself [21, 22, 43-47]. They also revealed that public bike-sharing could decrease the use of private cars. However, these results were mainly from the analysis of survey data, such as evaluating the change in habitual travel modes as a result of the emergence of a bikesharing system $[22,43,44]$, willingness to shift from cars to bike-sharing [45], and willingness to make the bike-sharing trip by car if bike-sharing was not available [21, 46]. With regard to other bicycle infrastructure, based on aggregate data from different sources in America, Stewart [48] built three regression models to examine the impact on car usage. The results revealed that when ignoring city- and year-dependent effects, every additional mile of bike lane per square mile resulted in $1.09 \%$ decrease in the percentage of people who drive to work. Obviously, existing studies only revealed the effect of bicycle infrastructure on car usage on a macrolevel. The results showed that the increase in bicycle infrastructure caused a small change in the percentage of commuting trips by car. Nevertheless, travel mode choice is an individual and microlevel behaviour. Many details, such as the measurement of the effect of bicycle infrastructure on car usage and the factors that may influence the modal shift from private cars to bicycles, have not been explored yet. These details are important to the design of urban road facilities and to infrastructure investment.

To explore the above details, this study investigates the relationship between bicycle infrastructure and car usage at a microlevel. Similar to most of the previous studies, the data of this study were collected by an on-site questionnaire survey in Huhhot. Then, a flexible model, mixed logit with random coefficients, was established to explore the factors that influence the individual mode choice behaviour. Based on this model, the effect of cycling infrastructure on the use of cars was investigated quantitatively.

\section{Study Area and Data Collection}

3.1. Study Area. Huhhot, the capital city of the Inner Mongolia Autonomous Region in China, is located in the northwest, around $500 \mathrm{~km}$ away from Beijing (Figure 1(a)). The landscape here is flat with a mean gradient of 3-5 degrees. The climate is mild with no severe cold in the winter and no heat in the summer. There are four districts, nine counties, and one banner administrated by the Huhhot city government. Among them, four districts, named Huimin, Yuquan, Xincheng, and Saihan, make up the entire urban area with a total area of $2,065 \mathrm{~km}^{2}$ (Figure $1(\mathrm{~b})$ ), which is home to a 1.35 million residents' population as recorded in 2018. This study focuses on the central urban area of Huhhot covering an area of $309.4 \mathrm{~km}^{2}$ (Figure 1(b)), because Huhhot has been one of the top 10 congested cities in the last three years and the traffic condition in this area is poor.

According to the annual report on road network density in major Chinese cities, the road network density in central Huhhot corresponds to $4.24 \mathrm{~km} / \mathrm{km}^{2}$, which is comparatively low. Nevertheless, the number of motor vehicles in Huhhot city is not low and has grown rapidly. This number was 1.22 million by the end of 2019. As a result, the traffic supply and demand in Huhhot is unbalanced. Based on this background, the bike-sharing system was introduced in Huhhot in 2013. Up to 2017, 317 bike-share stations had been built and 0.10 million bicycles had been introduced to the market. The average daily rent and daily return volume corresponded to 0.04 million in 2017. Furthermore, dockless bike-sharing systems such as Ofo, Mobike, Haluo, and Meituan have also developed rapidly in Huhhot. However, the construction of bicycle infrastructure here is not optimistic. In order to solve the problem of parking, several 


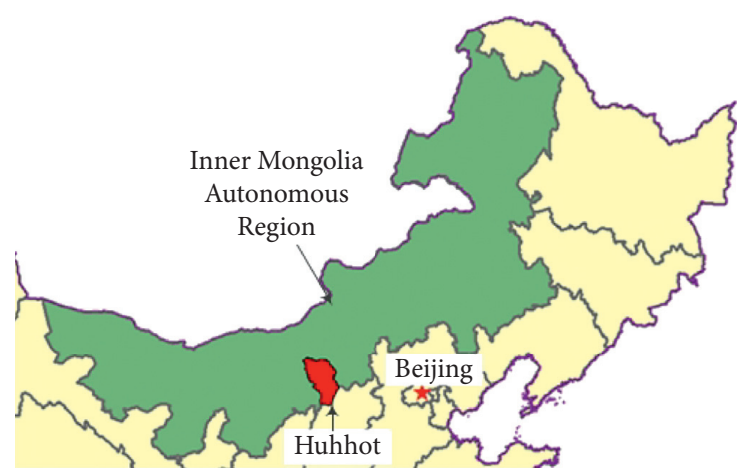

(a)

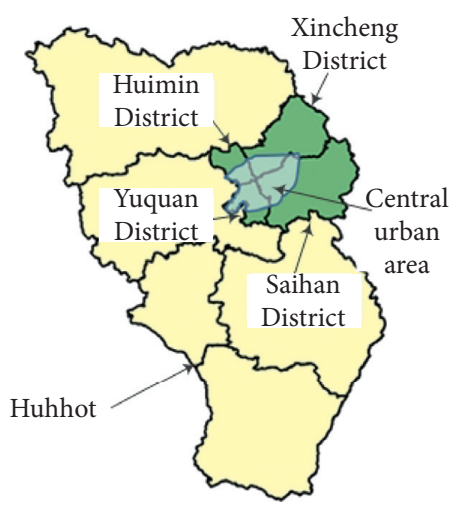

(b)

FIgure 1: Location and divisions of Huhhot. (a) Location of Huhhot. (b) Division of Huhhot.

nonmotorized lanes are occupied for parking spaces or driving (see Figure 2) and the cycling environment in Huhhot is not desirable. To this end, reasonable planning and utilization of the limited road resources in Huhhot are very important and need to be handled in a prudent way.

3.2. Data Collection. In order to obtain trip data about individuals' preferences, a stated preference (SP) survey was conducted among residents accustomed to driving in Huhhot. The SP survey is a discrete choice experiment and is widely used in the analysis of travel preferences or anticipated travel choices.

The questionnaire consisted of two parts. The first part was about individual characteristics, including gender, year of birth, monthly income, education, car ownership, and frequency of driving per week. The second part was designed to collect two types of preference data. One was about the willingness of individuals to reduce the number of their car trips in the case of a perfect bicycle system. Here, the perfect bicycle system mainly involves higher accessibility of public bicycles and a better cycling environment. In addition, despite understanding individuals' willingness to reduce their car usage, it is not clear how much they will reduce. When reducing their car usage, they may give up the trip or convert to the bus or taxi and so forth. Then, the change in the use of bicycles cannot be known. The answers to these problems can provide important references to the design of urban road facilities. Therefore, the other preference data were about individuals' choice problems. Here, each individual faced a choice among three alternatives representing three different travel modes: driving a car, riding a bicycle, and others. The attributes of each alternative are also presented in the questionnaire.

Travel mode choice behaviour is complex and involves many factors. If we can drive to our destination cheaply and quickly, it is less likely to shift from cars to other modes, especially bicycles. Therefore, in order to motivate people to ride a bicycle instead of driving a car, it is necessary to improve the attraction of bicycles and at the same time increase the travel cost of driving. Then, the factors that may influence the use of private cars and bicycles should be included as the attributes of the corresponding alternatives. Through a review of relevant literature, the influencing factors are presented in Table 1.

According to Table 1, the convenience of a bicyclesharing system is a key attraction to the bicycle user [43]. Here, convenience can be measured directly by the walking distance to bike-share stations, which plays an important role in the arrangement of bicycle-sharing systems. In addition, the presence of bike lanes and traveling distance are also factors that influence bicycle usage. With regard to driving a car, traffic congestion, travel cost, and insufficient parking space are found to be the main factors influencing the modal shift to bicycles. Furthermore, in order to minimize car-based trips, many countries or cities take some economical means to intervene in car usage, such as raising parking fees and congestion pricing. Since congestion pricing is still under discussion in China, this factor is not included in the questionnaire. Based on these, the attributes of the alternatives considered in this study included traveling distance, walking distance to bike stations, bike lanes, parking fees, and travel time by car. Among them, parking fees can also be used to measure travel costs to a certain extent. Travel time by car is used to indicate traffic congestion condition.

Each attribute/factor had three levels. Because the different traveling distances correspond to different travel times by car under different traffic congestion conditions, Table 2 presents the factors and corresponding levels besides travel time. Because the bicycle is often used for shortdistance trips, the traveling distance was set to three levels: $1.5 \mathrm{~km}, 3 \mathrm{~km}$, and $4.5 \mathrm{~km}$. The service radius of each bus stop corresponds to $300 \mathrm{~m}$ and bicycle is sometimes used for the traveling to bus stops. Therefore, the values of walking distance were set to $100 \mathrm{~m}, 200 \mathrm{~m}$, and $300 \mathrm{~m}$. For the bike lanes, considering the actual situation in Huhhot, the three levels corresponded to none, part, and all, which indicated streets with no bike lanes, part of streets with bike lanes, and all streets with bike lanes, respectively. In the central urban area of Huhhot, on-street parking and some public parking are free. Other parking for restaurants, hotels, and shopping malls is charged from 2 yuan (US $0.30 \$$ ) to 4 yuan (US $0.60 \$$ ) per hour. Based on these, three levels of parking fees were set 

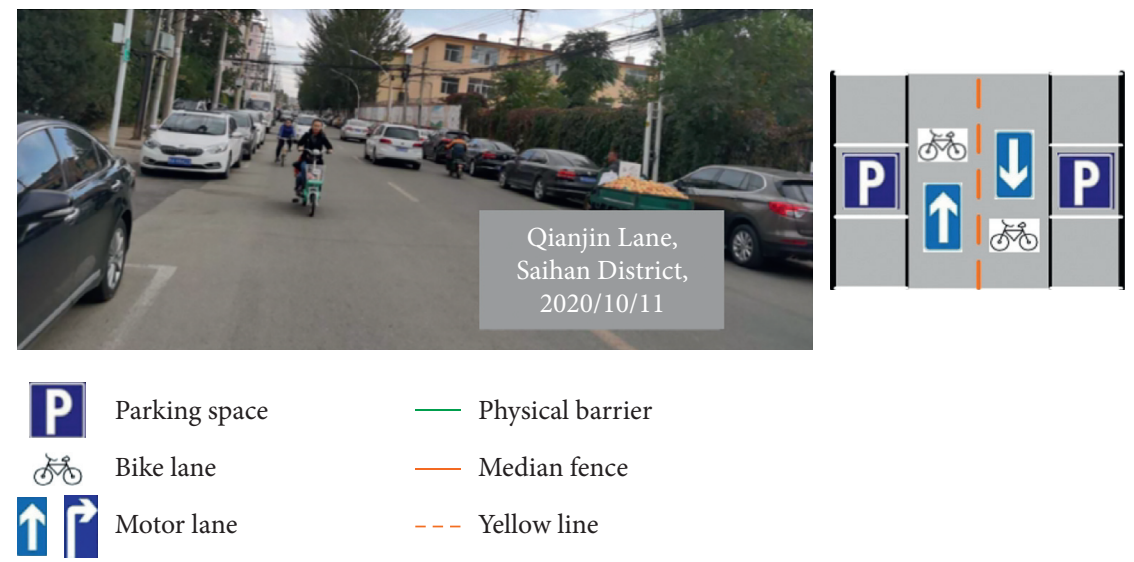

(a)
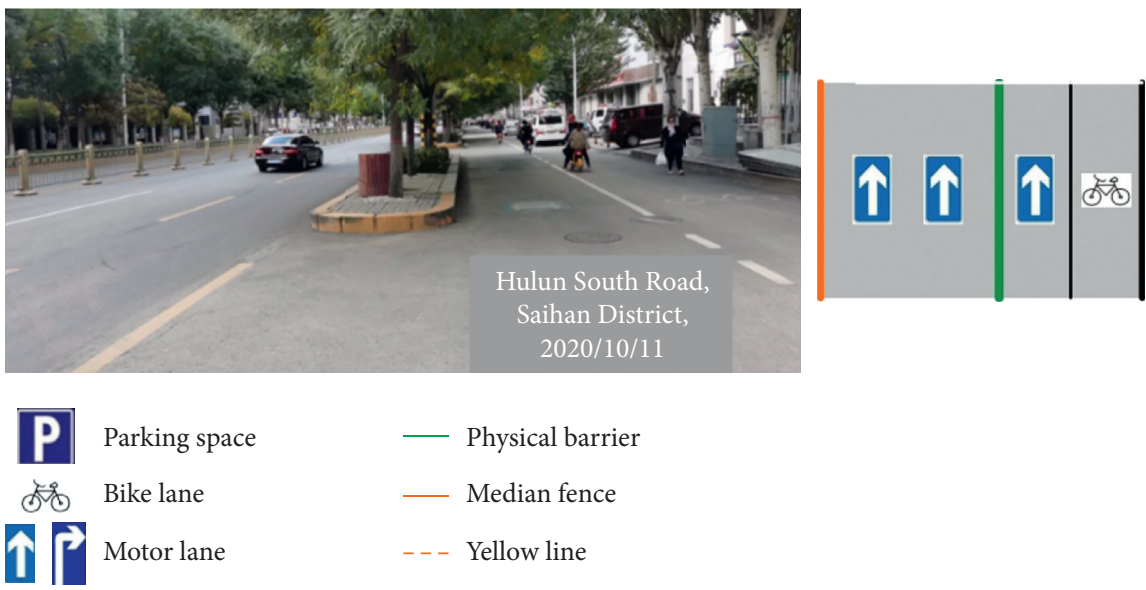

(b)
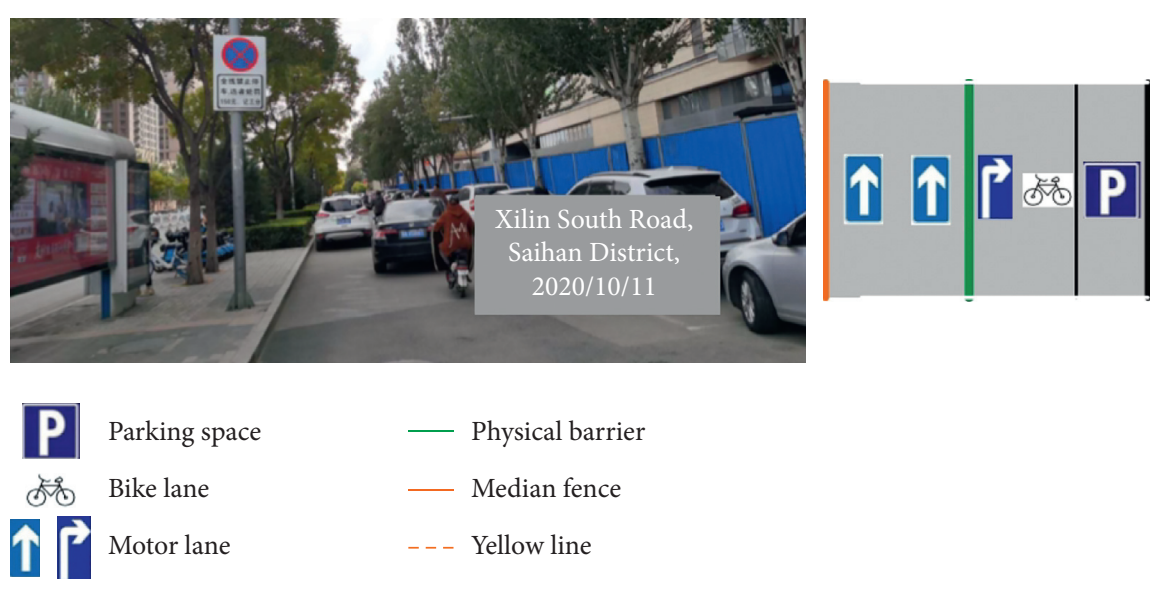

$$
\begin{aligned}
& \text { _ Physical barrier } \\
& \text { __ Median fence } \\
& -- \text { - Yellow line }
\end{aligned}
$$

(c)

FIgURE 2: Diagram of nonmotorized lanes used for parking or driving. (a) Mixed traffic road with on-street parking. (b) Part of nonmotorized lane used for driving. (c) Part of nonmotorized lane used for parking and driving.

to 0 yuan/h (US $0 \$ / h$ ), 2 yuan/h (US $0.30 \$ / h$ ) and 4 yuan/h (US $0.60 \$ / h$ ). In addition, travel time by car for different traveling distances was set by considering the average waiting time at signed road intersections, as shown in $\mathrm{Ta}$ ble 3 . In the questionnaire, traveling distance was treated as a precondition. With regard to the remaining four factors, an orthogonal experiment design was used to select several representative combinations of factorial levels, in which each factorial level appears the same number of times for any factor and each pair of factorial levels appears the same number of times for any pair of factors. Finally, the representative combinations of factorial levels are uniformly distributed and comparable. Based on this combination, the effect of each factor can be investigated separately. Regarding 
TABLe 1: Factors that may influence the use of bicycles and private cars.

Travel mode
$\begin{array}{r}\text { Convenience was found to be the main motivation factor for the use of bicycles [26, 27, 49, 50] } \\ \text { The presence of bicycle lanes tended to increase the bicycle usage [16, 17, 36] }\end{array}$
The likeliness to use bicycles was inclined to decrease as the riding distance increases [5, 18, 51, 52]
The bike-sharing may reduce personal driving for short-distance trips [45, 50, 53, 54]

TABLE 2: Value of factors in SP survey.

\begin{tabular}{lccc}
\hline Factors & Level 1 & Level 2 & Level 3 \\
\hline Traveling distance & $1.5 \mathrm{~km}$ & $3.0 \mathrm{~km}$ & $4.5 \mathrm{~km}$ \\
Walking distance to bike stations & $100 \mathrm{~m}$ & $200 \mathrm{~m}$ & $300 \mathrm{~m}$ \\
Bike lanes & None & Part & All \\
Parking fees & 0 yuan $/ \mathrm{h}(\mathrm{US} 0 \$ \mathrm{~h})$ & 2 yuan $/ \mathrm{h}(\mathrm{US} 0.30 \$ / \mathrm{h})$ & 4 yuan $/ \mathrm{h}(\mathrm{US} 0.60 \$ / \mathrm{h})$ \\
\hline
\end{tabular}

TABLE 3: Levels of travel time for different traveling distances.

\begin{tabular}{lccc}
\hline $\begin{array}{l}\text { Traveling distance } \\
(\mathrm{km})\end{array}$ & $\begin{array}{c}\text { Level } 1 \\
(\mathrm{~min})\end{array}$ & $\begin{array}{c}\text { Level } 2 \\
(\min )\end{array}$ & $\begin{array}{c}\text { Level 3 } \\
(\mathrm{min})\end{array}$ \\
\hline 1.5 & 6 & 11 & 20 \\
3.0 & 10 & 18 & 30 \\
4.5 & 13 & 25 & 40 \\
\hline
\end{tabular}

four factors with three levels, nine scenarios could be generated in total by the orthogonal experimental design. Combined with three distances, the total number of scenarios to be surveyed corresponded to 27. Details of the questionnaire are provided as the supplemental file.

The on-site questionnaire survey was conducted in some parking lots of shopping malls and enterprise units in the central urban area of Huhhot. The survey time lasted from April 17 to April 22, 2018, by the staffs of Huhhot Chenghuan Public Bicycle Company. Furthermore, facing the entire set of 27 scenarios may make respondents feel bored or impatient, which will influence the authenticity of their answers. In order to avoid respondents' impatience and improve the effectiveness of their answers, the 27 scenarios were divided into three random groups, and then each group of nine scenarios would be faced by the respondents.

A total of 576 respondents completed the questionnaires. In order to investigate the effect of bicycle infrastructure on car usage, only questionnaires in which driving was done at least twice a week were used for analysis. Finally, there were 364 valid questionnaires used to model.

Among these respondents, the percentages of male and female respondents were $51.9 \%$ and $48.1 \%$, respectively, which were close to the percentages of males and females in the city census $(50.9 \%$ and $49.1 \%$, respectively) [57]. Their average age corresponds to 37 with a standard deviation of 9 , indicating that the age distribution of respondents is relatively wide. Furthermore, $67.9 \%$ of respondents had a monthly income between 2000 and 6000 yuan (US \$302-906). According to data from the 2019 Huhhot Statistical Yearbook, the average monthly disposable income per person corresponds to 2973.50 yuan (US \$449). It can be found that the monthly income between our samples and the city census are roughly consistent. The samples of this survey have a certain degree of representativeness.

\section{Methodology}

The most popular method used to capture the individual's choice behaviour is the logit model, which is usually derived based on an assumption of utility maximization. Let an individual, labelled $n$, choose among $J$ alternatives under each choice scenario. The latent utility that individual $n$ obtains from alternative $j(j=1,2, \ldots, J)$ is assumed as follows:

$$
U_{n j}=\alpha^{\prime} x_{j}+\beta^{\prime} z_{n j}+\varepsilon_{n j},
$$

where $x_{j}$ is the vector consisting of observed attributes that are related to alternative $j$ and $z_{n j}$ is the vector containing observed attributes related to alternative $j$ and individual n. $\alpha$ and $\beta$ are the vectors of coefficients that need to be estimated. Parameter $\varepsilon_{n j}$ corresponds to the unobserved attributes that influence individuals' utility and is assumed to be i.i.d. distributed extreme value (also known as Gumbel distribution).

In the standard logit model, the estimated coefficients $(\alpha$ and $\beta$ ) are fixed, which results in some limitations. One of them is that the logit model cannot capture preference variation. The importance of each attribute is always different for each individual and may be influenced by observed characteristics as well as unobserved variables. For example, walking distance to bike stations is very important for individuals with walking disorders but secondary to those who enjoy sports. Nevertheless, the standard logit model with fixed coefficients cannot measure the difference in individuals' preferences for the same specific attributes. The IIA property is another limitation of the logit model. This means that an improvement in bicycle infrastructure will result in the same percentage drop in the choice probabilities for all other travel modes, which is inconsistent with reality. Therefore, to capture real choice behaviour and explain the effect of bicycle infrastructure on car usage, the flexible model, mixed logit with random coefficients, is used in this 
study. In the mixed logit model, the utility of individual $n$ for alternative $j(j=1,2, \ldots, J)$ is specified as follows:

$$
U_{n j}=\alpha_{n}^{\prime} x_{j}+\beta^{\prime} z_{n j}+\varepsilon_{n j}
$$

Except for $\alpha_{n}$, other parameters are the same as above. The coefficient vector $\alpha_{n}$ corresponds to individual's preferences and varies across individuals. It is assumed to be random with the density $f(\alpha)$. The unconditional probability of individual $n$ for alternative $i$ is expressed as follows [58]:

$$
p_{n i}=\int \frac{e^{\alpha^{\prime} x_{i}+\beta^{\prime} z_{n i}}}{\sum_{j=1}^{J} e^{\alpha^{\prime} x_{j}+\beta^{\prime} z_{n j}}} f(\alpha \mid \theta) \mathrm{d} \alpha,
$$

where $\theta$ is the parameter set used to describe the probability density function $f(\alpha)$. If $\alpha_{n}$ is fixed, the density $f(\alpha)$ can be expressed as $f\left(\alpha_{n}\right)=1$ with $\alpha_{n}=a$ and $f\left(\alpha_{n}\right)=0$ with $\alpha_{n} \neq a$. If the coefficient $\alpha_{n}$ is random, it is generally assumed to obey a normal or lognormal distribution with mean $a$ and standard deviation $s: \alpha_{n} \sim N(a, s)$ or $\ln \alpha_{n} \sim N(a, s)$. Consequently, the estimation of $\alpha_{n}$ becomes an estimation of the parameters $a$ and $s$.

In this study, considering that different individuals place different values on the usage of cars and bicycles, which may depend on the unobserved individuals' characteristics, two random terms are introduced into the model and assumed to be independent and distributed normally: $\alpha_{n \mathrm{ASC}-c} \sim N\left(a_{c}, s_{c}^{2}\right)$ and $\alpha_{n \mathrm{ASC}-b} \sim N\left(a_{b}, s_{b}^{2}\right)$. Here, the introduction of random terms can relax the restrictive independence assumption in the standard logit model. It can be stated that driving and cycling are preferred by approximately $\Phi\left(a_{c} / s_{c}\right)$ and $\Phi\left(a_{b} / s_{b}\right)$ of individuals, respectively. Furthermore, due to the different individuals' preferences, the coefficients of travel time and walking distance to bike stations are also assumed to be random. Because these two variables are known to be negative for each individual, their coefficients have the same sign for all individuals. Therefore, they are assumed to be distributed lognormally across individuals: $\ln \alpha_{n t t} \sim N\left(a_{t t}, s_{t t}^{2}\right)$ and $\ln \alpha_{n w d} \sim N\left(a_{w d}, s_{w d}^{2}\right)$. By definition, it can be derived that these two coefficients $\left(\alpha_{n t t}\right.$ and $\left.\alpha_{n w d}\right)$ themselves have medians $\exp \left(a_{t t}\right)$ and $\exp \left(a_{w d}\right)$, respectively. Meanwhile, their means correspond to $\exp \left(a_{t t}+s_{t t}^{2} / 2\right)$ and $\exp \left(a_{w d}+s_{w d}^{2} / 2\right)$. Furthermore, their variances can be calculated as $\exp \left(2 a_{t t}+s_{t t}^{2}\right)\left[\exp \left(s_{t t}^{2}\right)-\right.$ 1] and $\exp \left(2 a_{w d}+s_{w d}^{2}\right)\left[\exp \left(s_{w d}^{2}\right)-1\right]$. The remaining coefficients are assumed to be constant.

\section{Model Results}

5.1. Willingness to Reduce Driving Frequency. A total of 274 respondents stated that they would like to reduce their car usage in the case of a perfect bicycle system, which accounted for $75.1 \%$ of the total valid respondents. This indicates that improvement in the bicycle system has a significant impact on the driving frequency of individuals. Furthermore, the differences in overall willingness to reduce driving frequency caused by individual characteristics are presented in Table 4.
It can be found that a slightly larger number of male respondents are willing to cut down their car usage, which is in line with past studies that found cycling to be unpopular with women $[59,60]$. With regard to income, it is found that those who own relatively higher monthly income are more likely to reduce their frequency of driving, which further verifies the result of previous studies that the income of bicycle-sharing participants tended to be higher $[14,38,61,62]$. Moreover, people with higher education levels tend to reduce their car usage, corresponding to the result of Braun et al. [53] that cycling was more prevalent among those with education beyond high school. From Table 4, it is also found that the willingness of people owning cars to drop their driving frequency is slightly stronger. This could be explained by the fact that the attraction of driving to people without cars is relatively higher and they are less likely to reduce the use of cars.

In terms of weekly driving frequency, $75.6 \%$ of respondents driving 2-4 times per week, which make up $22.5 \%$ of the total studied respondents, are willing to reduce their frequency of driving, $81.7 \%$ of those driving 4-6 times per week accounting for $28.6 \%$ of the respondents would like to cut down their car usage, and $71.3 \%$ of those drive a car more than 6 times per week, accounting for $48.9 \%$, are likely to drop their driving frequency. Although all the respondents had strong attitudes toward reducing their car usage, the willingness of those who travel less than four or more than six times per week is relatively weaker. A possible explanation for this result is that the travel purposes of those who drive 4-6 times per week are more likely to go to work. Due to the fixed working time, it is reasonable and predictable to change their travel mode if there is a better choice. Consequently, their willingness to reduce driving frequency is slightly strong.

5.2. Mixed Logit Model Results. The effect of bicycle infrastructure is analyzed based on the mixed logit model. Generally, the maximum simulated likelihood approach is used to estimate the parameters $\theta$ and $\beta$. Based on this, the corresponding coefficients were also estimated. Because the distribution of each of the coefficients is specified, the probabilities of individual $n$ for alternative $i$ (equation (3)) can be simulated by drawing $\alpha$ from their density function $f(\alpha)$ under any given value of $\theta$.

$$
\breve{p}_{n}(i \mid \theta t, n q \beta)=\frac{1}{R} \sum_{r=1}^{R} \frac{e^{\alpha^{r \prime} x_{i}+\beta^{\prime} z_{n i}}}{\sum_{j=1}^{J} e^{\alpha^{r \prime} x_{j}+\beta^{\prime} z_{n j}} .}
$$

Here, $R$ corresponds to the number of drawings. In this study, $R$ is set to 1000 and $\bar{p}_{n}(i \mid \theta t, n \beta)$ is the unbiased estimation of $p_{n}(i \mid \theta, \beta)$. Let $y_{n}=\left\{y_{n 1}, y_{n 2}, \ldots, y_{n T}\right\}$ denote the choice results of individual $n$ under all choice scenarios. $T$ is the number of choice scenarios faced by individual $n$. The simulated log-likelihood function becomes

$$
L L(\theta, \beta)=\sum_{n=1}^{N} \sum_{t=1}^{T} \ln \breve{p}_{n}\left(y_{n t} \mid \theta, \beta\right) .
$$


TABLE 4: Description of willingness to reduce driving by individual characteristics.

\begin{tabular}{|c|c|c|c|}
\hline Variables & Number & $\begin{array}{c}\text { Number of those willing to reduce } \\
\text { driving }\end{array}$ & $\begin{array}{c}\text { Percentage of those willing to reduce } \\
\text { driving }\end{array}$ \\
\hline \multicolumn{4}{|l|}{ Gender } \\
\hline Male & 189 & 143 & 75.7 \\
\hline Female & 175 & 131 & 74.9 \\
\hline \multicolumn{4}{|l|}{ Monthly income } \\
\hline $0 \sim 2000$ yuan (US $\$ 0-302$ ) & 30 & 20 & 66.7 \\
\hline $2000 \sim 4000$ yuan (US $\$ 302-604$ ) & 127 & 94 & 74.0 \\
\hline $4000 \sim 6000$ yuan (US $\$ 604-906$ ) & 120 & 90 & 75.0 \\
\hline $6000 \sim 8000$ yuan (US $\$ 906-1208$ ) & 45 & 37 & 82.2 \\
\hline $\begin{array}{l}\text { More than } 8000 \text { yuan (more than US } \\
\$ 1208 \text { ) }\end{array}$ & 42 & 31 & 73.8 \\
\hline \multicolumn{4}{|l|}{ Education } \\
\hline Below bachelor & 183 & 131 & 71.6 \\
\hline Bachelor & 140 & 107 & 76.3 \\
\hline Postgraduate or above & 41 & 36 & 87.8 \\
\hline \multicolumn{4}{|l|}{ Car in household } \\
\hline Yes & 284 & 215 & 75.7 \\
\hline No & 80 & 59 & 73.8 \\
\hline \multicolumn{4}{|l|}{ Driving frequency } \\
\hline $2-4$ times & 82 & 62 & 75.6 \\
\hline 4-6 times & 104 & 85 & 81.7 \\
\hline More than 6 times & 178 & 127 & 71.3 \\
\hline
\end{tabular}

Then, the parameters $\theta$ and fixed coefficients $\beta$ are estimated by maximizing $L L(\theta, \beta)$.

In this study, each individual faced 9 choice scenarios. Because some individuals did not complete all the choice scenarios, a total of 3218 observations were used to estimate all the random and fixed coefficients. The estimation was calculated using Stata 15. The results are presented in Table 5 . In addition, the standard logit model was also built. The log-likelihood values at the convergence of the mixed logit model and the standard logit model correspond to -1992.98 and -2704.32 , respectively. The adjusted likelihood ratio indexes of the two models are 0.4290 and 0.2275 . It can be seen that the mixed logit model provides better fitting in comparison with the standard model.

With regard to two variables, $\mathrm{ASC}_{\mathrm{car}}$ and $\mathrm{ASC}_{\mathrm{bicycle}}$, which refer to driving a car and riding a bicycle, respectively, their constant coefficients in the standard logit model are estimated. In the mixed logit model, they are assumed to obey a normal distribution. The estimated standard deviations of these two coefficients are highly significant, which indicates that there are considerable variations in individuals' attitudes toward driving a car and riding a bicycle. In addition, the mean of the coefficient for riding a bicycle is significant, positive, and considerably different from 0 , which suggests that substantial respondents place a positive value on riding a bicycle. According to the normal distribution $N(4.8127,2.5340)$, we can derive that riding a bicycle is preferred by almost $97 \%$ of individuals and avoided by the remaining $3 \%$. Meanwhile, the mean of the coefficient for driving is also significant and positive, which indicates that there is a distinct difference in individuals' preference between driving a car and other modes. With regard to the normal distribution $N$ (3.0339,
2.4412), we can see that almost $89 \%$ of individuals have a positive attitude toward the use of cars. Based on the above results, it can be concluded that, assuming that all the other variables are constant, relatively more individuals prefer riding a bicycle to other travel modes, including driving. These findings are important to traffic policymakers and further indicate that improvement in the bicycle system will attract sizeable car-users to turn into bike-users.

Considering the other two variables, travel time by car and walking distance to bike stations which are negative factors for each individual, their coefficients are given a lognormal distribution. The significant estimated standard deviations suggest that the negative importance of these two variables varies across all individuals. According to the lognormal distribution, the medians of these two coefficients correspond to 0.0272 and 0.0026 , respectively. Their means can be obtained as 0.1362 and 0.0038 and their standard deviations can be calculated as 0.6677 and 0.0040 , respectively. With regard to the travel time specified to driving a car, the ratio of the coefficient for travel time multiplied by 10 to the coefficient for parking fees, which is always used to measure the amount that individuals are willing to pay to reduce their travel time, has an estimated mean of $0.1362 \times 10 / 0.1751=7.78$ and estimated standard deviation of $0.6677 \times 10 / 0.1751=38.13$. It is indicated that the average parking fees to shorten the travel time of 10 minutes is 7.78 yuan $/ \mathrm{h}$ (US $1.17 \$ / \mathrm{h}$ ). This result also implies that an additional 10-minute travel time has the same importance on the utility of driving a car as the average parking fees increased by 7.78 yuan/h (US $1.17 \$ / \mathrm{h}$ ). In addition, there is a significant and considerable variation in individuals' willingness to pay for the reduction in travel time by car. These results further indicate that the mixed logit model provides a 
TABLE 5: Estimation results of the models.

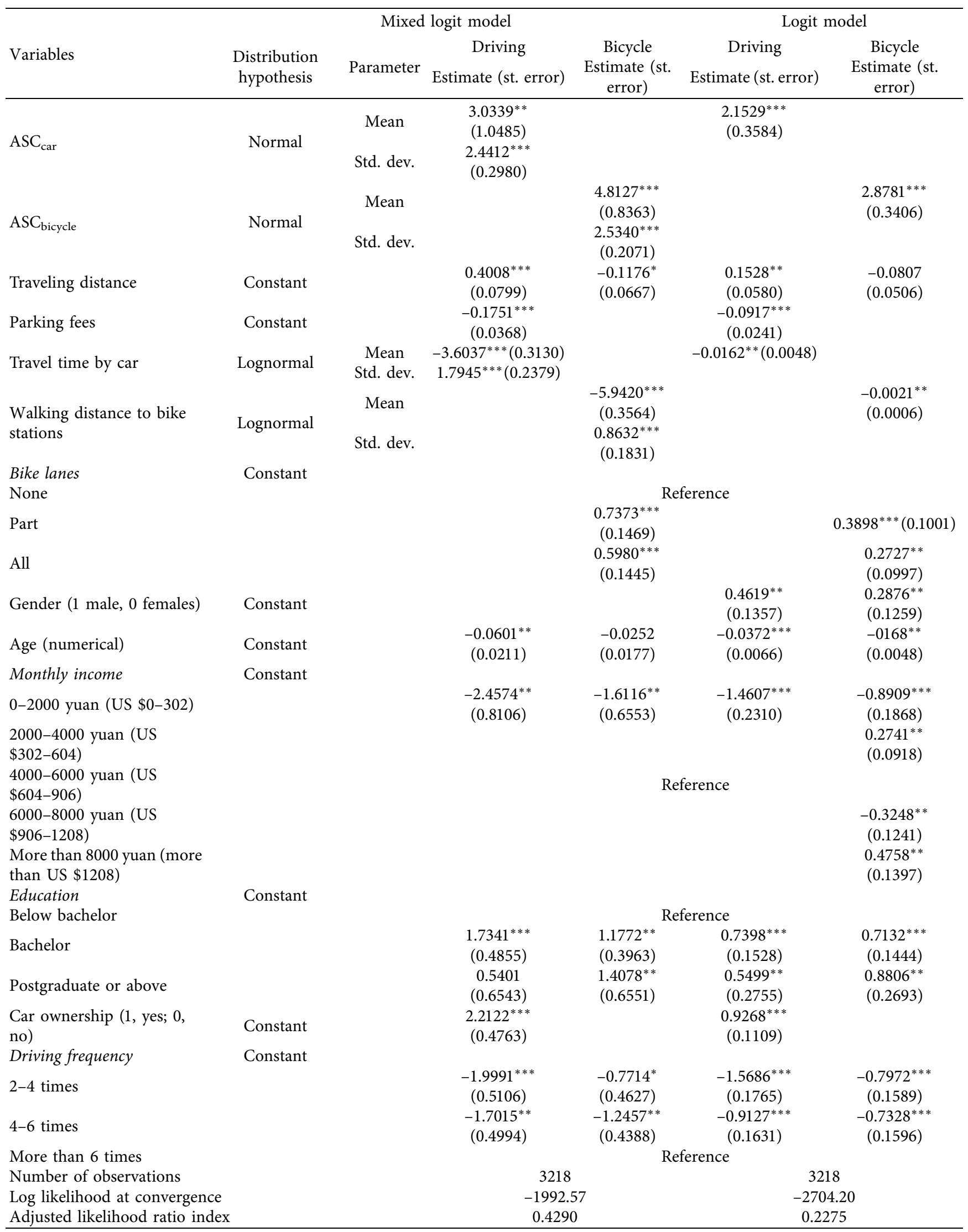

*** Significant at the 0.001 level. ${ }^{* *}$ Significant at the 0.05 level. ${ }^{*}$ Significant at the 0.1 level. 
better representation of this choice problem than the standard logit model.

To our expectation, longer traveling distance will stimulate the use of private cars significantly (0.4008) and reduce the utility of riding a bicycle $(-0.1175)$. This indicates that the effect of improvement in the bicycle system on driving a car becomes more significant as the traveling distance decreases. Therefore, for the long-distance travel, other modes, such as public transport, need to be built and improved.

The coefficient of parking fees is negative and significant $(-0.1751)$, indicating that an increase in parking fees will force individuals to reduce their car usage. This result provides further evidence that economic leverage has an effective regulation role for the use of private cars. However, raising the parking fees requires careful consideration of the pros and cons from the perspective of people's livelihoods.

As expected, the coefficients of bike lanes are significant and positive (0.7373 and 0.5680 ), indicating that the construction of dedicated bike lanes will significantly improve the utility of riding a bicycle. Furthermore, the coefficient for part of streets with bike lanes is greater than that of all streets with bike lanes, which may explain that the impact of bike lanes has the upper limit. This suggests that providing bike lanes could increase bicycle's attractiveness, but this does not mean the more the better. Therefore, it is important to construct a certain number of bike lanes, and too many bike lanes will not increase the use of bicycles.

In terms of the variables related to attributes of individuals, as distinct from the standard logit model, except age for driving car, the coefficients of gender and age are not significant here. This may be because the random coefficients of $\mathrm{ASC}_{\mathrm{car}}$ and $\mathrm{ASC}_{\text {bicycle }}$ are specified in the mixed logit model. Their significant standard deviations indicate that these coefficients do vary across individuals. These variations are related to both the observed and unobserved attributes of individuals. Then, the random coefficients specified in the mixed logit model may capture the variations in individuals' preferences, which are related to gender and age. Considering the variables related to monthly income, individuals with income less than 2000 yuan (US \$302) per month have negative attitudes toward driving a car as well as riding a bicycle. In addition, the coefficient of monthly income (-2.4574) for driving is less than that for riding a bicycle (-1.6116), indicating that those with income less than 2000 yuan (US \$302) per month prefer riding a bicycle to driving significantly. With regard to the variables related to educational background, individuals with a higher level of education have positive attitudes toward the use of cars and bicycles. Moreover, by comparing their coefficients, it can be found that the coefficient of postgraduate degree or above for driving (0.5401) is less than that for riding a bicycle (1.4078), but the coefficient of bachelor degree for driving (1.7341) is greater than that for riding a bicycle (1.1772). These results reflect that individuals who have postgraduate degree or above prefer cycling to driving, but those with bachelor degree place a higher value on the use of cars. The coefficient of the car in households is estimated to be 2.2122 , reflecting that individuals who own cars have a strong willingness to driving. For the variables related to the frequency of driving per week, in line with the standard logit model, their coefficients are estimated to be significant for driving a car as well as riding a bicycle. It can be found that individuals with less driving frequency per week have negative attitudes toward driving and cycling, respectively. Considering the difference in these coefficients $(-1.9991-(-0.7714)=-$ 1.2277 for the driving frequency of 2-4 times per week and $-1.7015-(-1.2457)=-0.4558$ for the driving frequency of 4-6 times), it can be deduced that individuals who use cars less times per week place a higher value on riding a bicycle. This also indicates that these individuals prefer riding a bicycle to driving a car. This result further explains the phenomenon obtained by the SP survey that most of the respondents are willing to reduce their car usage.

\section{Quantifying Effect of Bicycle Infrastructure on Car Usage}

Based on the mixed logit model, reducing the walking distance and constructing dedicated bike lanes will significantly improve the utility of riding a bicycle. As a result, assuming that the other variables are constant, the probability of riding a bicycle will increase accordingly. Because the sum of probabilities of all alternatives is equal to 1 , the increase in the probability of riding a bicycle means a decrease in the probabilities of the other two alternatives, which correspond to driving a car and others. Hence, the improvement in the utility of riding a bicycle may reduce the probability of driving a car as well as the probability of others. In the light of equation (3), the change in the probability of each travel mode can be quantitatively evaluated. Based on this, the effect of bicycle infrastructure on the use of private cars is investigated next.

6.1. Measurement Index. Before quantitative analysis, an index needs to be introduced to measure the effect of bicycle infrastructure on car usage. Generally, the crosselasticity, which is denoted as the percentage change in the probability for one alternative given a percentage change in $m$ th attribute of another alternative [58], is used to capture this problem. However, the cross-elasticity is not suitable for categorical variables, such as the presence of bike lanes, because it is impossible to calculate the percentage change in bike lanes. Furthermore, as stated earlier, the improvement in bicycle infrastructure may lead to a reduction in the probability of driving, which can be obtained by equation (3). Meanwhile, this reduction in the probability of driving can also be achieved by other measures, such as increasing the parking fees. Then, in order to compare with existing economical means used to intervene in car usage, based on the constraints for maintaining the effect on car usage equal, the equivalent change in parking fees for the improvement in bicycle infrastructure will meet the following condition: 


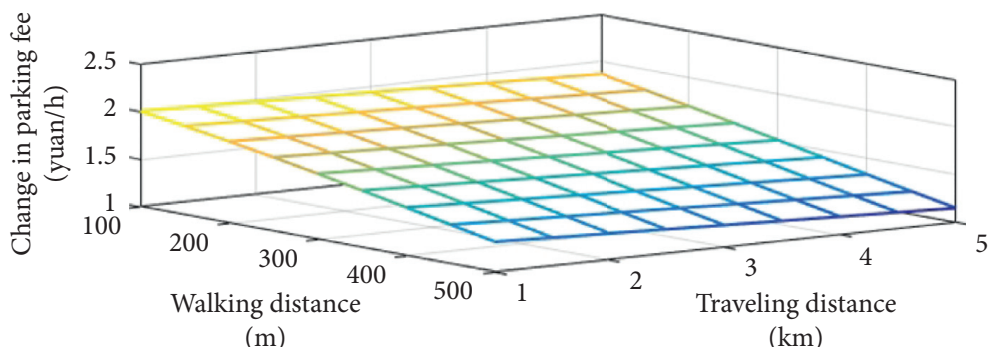

(a)

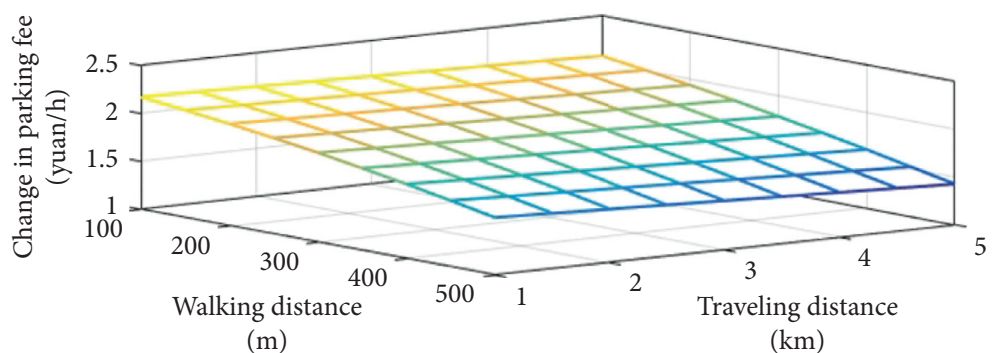

(b)

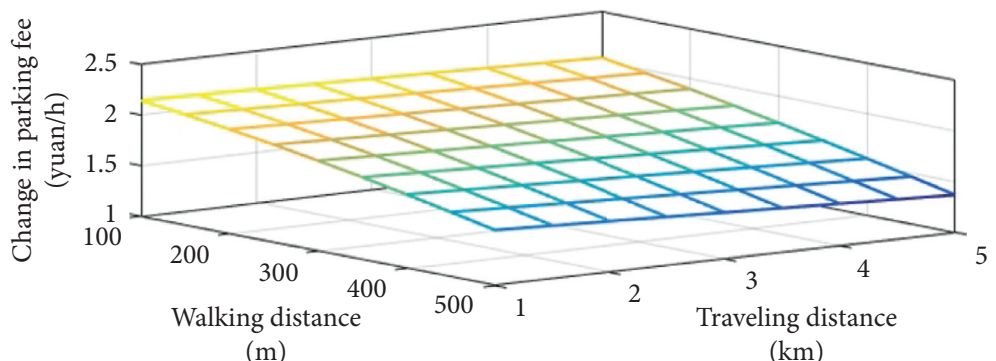

(c)

Figure 3: Average change in parking fees for walking distance reduced by $100 \mathrm{~m}$. (a) No street with bike lanes. (b) Part of streets with bike lanes. (c) All streets with bike lanes.

$$
\int \frac{e^{V_{n 1}+\alpha_{p f} \Delta x_{p f}}}{1+e^{V_{n 1}+\alpha_{p f} \Delta x_{p f}}+e^{V_{n 2}}} f(\alpha \mid \theta) d \alpha=\int \frac{e^{V_{n 1}}}{1+e^{V_{n 1}}+e^{V_{n 2}+\alpha_{b f} \Delta x_{b f}}} f(\alpha \mid \theta) d \alpha .
$$

Here $\Delta x_{p f}$ and $\Delta x_{b f}$ correspond to the changes in parking fees and bicycle infrastructure. It can be seen that the change in parking fees $\Delta x_{p f}$ and the change in bicycle infrastructure $\Delta x_{b f}$ have the same effect on the probability of driving a car. $\alpha_{p f}$ corresponds to the coefficient of parking fees and $\alpha_{b f}$ denotes the coefficient of bicycle infrastructure. $V_{n 1}$ and $V_{n 2}$ are the observed parts of utilities for driving a car and riding a bicycle under the given value of all variables in the mixed logit model.

With regard to each random coefficient in the mixed logit model, the parameters of samples were estimated and are presented in Table 5. Based on these, the individual-level parameters are calculated as

$$
\bar{\alpha}_{n}=\frac{\int \alpha \times P\left(y_{n t} \mid x_{n}, \alpha\right) f(\alpha \mid \theta) \mathrm{d} \alpha}{\int P\left(y_{n t} \mid x_{n}, \alpha\right) f(\alpha \mid \theta) \mathrm{d} \alpha} .
$$

Taking draws of $\alpha$ from $f(\alpha \mid \theta)$, the simulated parameters become

$$
\breve{\alpha}_{n}=\sum_{r} \frac{\alpha^{r} \times P\left(y_{n t} \mid x_{n}, \alpha^{r}\right)}{\sum_{r} P\left(y_{n t} \mid x_{n}, \alpha^{r}\right)}
$$

where $P\left(y_{n t} \mid x_{n}, \alpha\right)$ corresponds to the probability of an individual's choices and is expressed as

$$
P\left(y_{n t} \mid x_{n}, \alpha^{r}\right)=\prod_{t} \frac{e^{\alpha^{r \prime} x_{y_{n t}}+\beta^{\prime} z_{n y_{n t}}}}{\sum_{j=1}^{J} e^{\alpha^{r \prime} x_{j}+\beta^{\prime} z_{n j}}}
$$

Based on the individual-level parameters, we can derive the relation between $\Delta x_{p f}$ and $\Delta x_{b f}$ as follows:

$$
\Delta x_{p f}=\frac{1}{\beta_{p f}} \ln \frac{1+e^{V_{n 2}}}{1+e^{V_{n 2}+\alpha_{b f} \Delta x_{b f}}} .
$$

Because of the different attributes and coefficients, each individual has different utilities of each alternative. Then the equivalent change in parking fees which is derived from equation (10) is also different for each individual. In order to 


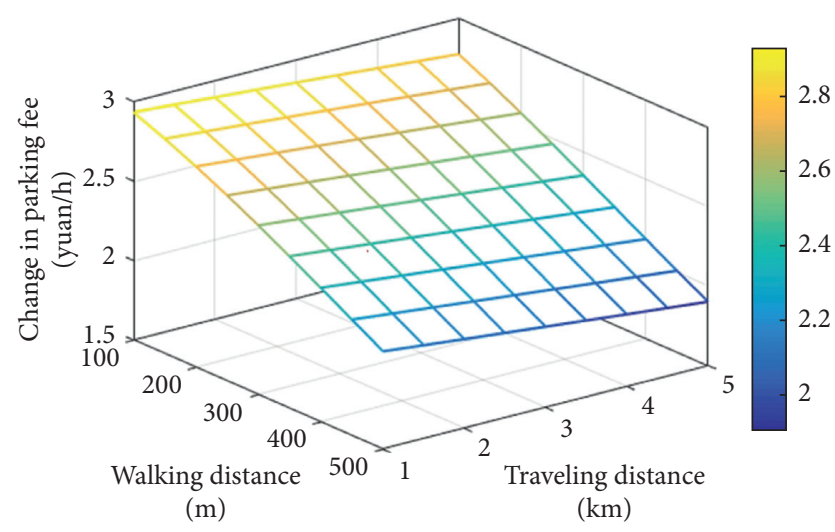

FIgURE 4: Average change in parking fees for constructing bike lanes.

ensure the universality and robustness of the results, the average change in parking fees among the total respondents is used for further analysis.

6.2. Effect of Bicycle Infrastructure. In this study, the effects of reducing the walking distance to bike stations and providing dedicated bike lanes on car usage are quantified and analyzed.

Considering the different traveling distances, the equivalent change in parking fees for a reduction of $100 \mathrm{~m}$ in the walking distance to bike stations is presented in Figure 3. By comparing Figures 3(a) 3(c), it can be found that whether or not the dedicated bike lanes are constructed, based on the constraints for keeping the effect on car usage equal, the effect of a $100 \mathrm{~m}$ reduction in walking distance to bicycle stations on the probability of driving is equivalent to that of almost 2.00 yuan $/ \mathrm{h}$ (US $0.30 \$ / \mathrm{h}$ ) increase in parking fees. Furthermore, as can be seen from Figure 3, the walking distance to bike stations has a distinct influence on the equivalent change in parking fees, but the impact of traveling distance is not obvious. The equivalent change in parking fees decreases with increasing walking distance to bike stations, indicating that the effect of reduction in walking distance is more distinct when this distance is short.

The equivalent change of parking fees for constructing bike lanes within the traveling range of each individual is presented in Figure 4. It can be found that providing dedicated bike lanes not only affects the utility of bicycles but also has a considerable effect on car usage. This effect is in line with additional parking fees of about 3.00 yuan/h (US $0.45 \$ / \mathrm{h}$ ). Moreover, the construction of dedicated bike lanes will reduce on-street parking; meanwhile, it may reduce or narrow the motor lanes. Then, travel time by car will increase and the utility of driving a car will also decline. Obviously, when considering this increased travel time, the equivalent change of parking fees to construction of dedicated bike lanes may be influenced. Because the average willingness to pay higher parking fees to reduce their travel time by 10 minutes corresponds to 7.78 yuan/h (US $1.17 \$ / \mathrm{h}$ ), it can be deduced that the effect of providing dedicated bike lanes will be dramatic. Compared to walking distance to bike stations, it can be indicated that the construction and improvement of bike lanes will be an effective method to increase the use of bicycles and reduce the probability of driving a car. Furthermore, as in the case of walking distance to bike stations, the effect of constructing bike lanes becomes more apparent with the decrease in walking distance to bike stations.

\section{Conclusions}

Developing bicycle-sharing system has been one of the popular measures to mitigate the traffic congestion. $\mathrm{Nu}$ merous cities are working to improve their bicycle infrastructure, including expanding bike lanes and optimizing the bicycle stations. The aim of this study is to quantitatively investigate the effect of bicycle infrastructure on car usage. Based on an SP survey conducted among the sampling residents accustomed to driving in Huhhot, China, a mixed logit model for travel mode choices of respondents was built. In the model, the coefficients of four variables were assumed to be normal or lognormal distributed. The estimated results show that the mixed logit model gives better fitting in comparison with the standard logit model.

It was found that there are considerable variations in individuals' attitudes toward the use of cars and bicycles. Riding a bicycle is preferred by almost $97 \%$ of individuals and avoided by the remaining $3 \%$. Furthermore, it is also shown that the coefficients of travel time and walking distance to bike stations do vary across individuals. Moreover, reducing the walking distance to bike stations and construction of dedicated bike lanes will increase the utility of riding a bicycle considerably. Furthermore, assuming the other variables to be constant, based on the constraints for keeping the effect on car usage equal, the equivalent change in parking fees for the improvement in bicycle infrastructure has been estimated in this study. The results show that the effect of a $100 \mathrm{~m}$ reduction in the walking distance to bicycle stations on the probability of driving is the same as that of approximately 2.00 yuan/h (US $0.30 \$ / \mathrm{h}$ ) increment of parking fees, and the effect of providing completed bike lanes is in line with additional parking fees of almost 3.00 yuan/h (US $0.45 \$ / \mathrm{h}$ ).

The above results can provide some reference for the rational allocation of infrastructure investment and road resources. Since the improvement in bike lanes will be an effective method to reduce the probability of driving a car and to raise the use of bicycles, traffic authorities should emphasize the construction of bike lanes, dedicated bike lanes in particular, which will also enhance traffic safety in cities such as Huhhot. Although the construction of bike lanes will occupy road resources and may worsen traffic congestion, the terrible traffic situation means the increase in travel time, which may further reduce the use of private cars. Then, the problem of traffic congestion will be improved gradually. In addition, the reduction of walking distance to bicycle stations has a distinct effect on car usage. Then, government departments should give preferential policies to public bike-share programs and encourage them to design bicycle stations reasonably. 
One limitation of this study is that the data used for model estimation comes from a SP survey. Since the preference choices of respondents in the SP survey may not be consistent with the reality after improving the bicycle infrastructure, the validation and reliability of the estimated results may be influenced. Other practical experiments need to be compensated and further validated. Furthermore, with regard to the effect of bicycle infrastructure on car usage, the equivalent changes in parking fees are estimated among the respondents. Thus, the universality of results may be limited. In order to ensure the validation of the estimated results, the actual responses of residents could be tracked while increasing bike stations as well as improving bike lanes. The joint mixed logit model can be estimated based on the combining data from SP and RP survey, which have been used widely [63] to yield valid estimation of the coefficients and predict mode choice behaviour. Moreover, for the universal equivalent changes in parking fees for improving bicycle infrastructure, the simulation method may be a good choice. Nevertheless, before the simulation, the distribution of individual characteristics will need to be derived from a large-scale survey. All these problems will be addressed in our future work.

\section{Data Availability}

The data used to support the model and analysis of this study are presented within the article.

\section{Conflicts of Interest}

The authors declare that they have no conflicts of interest.

\section{Acknowledgments}

The authors acknowledge Huhhot Chenghuan Public Bicycle Company for providing the basic data and the assistance in their surveys. This research was funded by the National Natural Science Foundation of China (Grant no. 71961024), the Natural Science Foundation of Inner Mongolia Autonomous Region (Grant no. 2020MS05060), the Science and Technology Construction Foundation of Inner Mongolia Transportation Commission (Grant no. NJ-2019-02), the "13th Five-Year" Plan of Educational Science Research in Inner Mongolia (Grant no. NGJGH2018016), and the Key Technology Research Plan of Inner Mongolia Autonomous Region (Grant no. 2019GG287).

\section{Supplementary Materials}

The supplementary file describes the questionnaire about bicycle-sharing system. (Supplementary Materials)

\section{References}

[1] R. Ewing, K. Bartholomew, S. Winkelman, J. Walters, and D. Chen, Growing Cooler: The Evidence on Urban Development and Climate Change, Urban Land Institute, Washington, DC, USA, 2009.

[2] A. Baghestani, M. Tayarani, M. Allahviranloo, and H. O. Gao, "Evaluating the traffic and emissions impacts of congestion pricing in New York city," Sustainability, vol. 12, no. 9, p. $3655,2020$.

[3] Y. Zhang, T. Thomas, M. Brussel, and M. Van Maarseveen, "Exploring the impact of built environment factors on the use of public bikes at bike stations: case study in Zhongshan, China," Journal of Transport Geography, vol. 58, pp. 59-70, 2017.

[4] S. Shaheen, S. Guzman, and H. Zhang, "Bikesharing in Europe, the Americas, and Asia: past, present, and future," Transportation Research Record, vol. 2143, no. 1, pp. 159-167, 2010.

[5] N. Maizlish, J. Woodcock, S. Co, B. Ostro, A. Fanai, and D. Fairley, "Health cobenefits and transportation-related reductions in greenhouse gas emissions in the san francisco bay area," American Journal of Public Health, vol. 103, no. 4, pp. 703-709, 2013.

[6] S. A. H. Zahabi, A. Chang, L. F. Miranda-Moreno, and Z. Patterson, "Exploring the link between the neighborhood typologies, bicycle infrastructure and commuting cycling over time and the potential impact on commuter GHG emissions," Transportation Research Part D: Transport and Environment, vol. 47, pp. 89-103, 2016.

[7] J. J. De Hartog, H. Boogaard, H. Nijland, and G. Hoek, "Do the health benefits of cycling outweigh the risks?" Environmental Health Perspectives, vol. 118, no. 8, pp. 1109-1116, 2010.

[8] J. Horner, Less Driving, More Saving: The Economic Benefits of Cutting Car Travel, Natural Resources Defense Council, Washington, DC, USA, 2012.

[9] P. Oja, S. Titze, A. Bauman et al., "Health benefits of cycling: a systematic review," Scandinavian Journal of Medicine \& Science in Sports, vol. 21, no. 4, pp. 496-509, 2011.

[10] A. Forsyth, K. J. Krizek, A. W. Agrawal, and E. Stonebraker, "Reliability testing of the pedestrian and bicycling survey (PABS) method," Journal of Physical Activity and Health, vol. 9, no. 5, pp. 677-688, 2012.

[11] J. Pucher, R. Buehler, D. R. Bassett, and A. L. Dannenberg, "Walking and cycling to health: a comparative analysis of city, state, and international data," American Journal of Public Health, vol. 100, no. 10, pp. 1986-1992, 2010.

[12] C. A. Celis-Morales, D. M. Lyall, P. Welsh et al., "Association between active commuting and incident cardiovascular disease, cancer, and mortality: prospective cohort study," $B M J$, vol. 357, p. j1456, 2017.

[13] J. Lee, S. Y. He, and D. W. Sohn, "Potential of converting short car trips to active trips: the role of the built environment in tour-based travel," Journal of Transport \& Health, vol. 7, pp. 134-148, 2017.

[14] J. Woodcock, M. Tainio, J. Cheshire, O. O’Brien, and A. Goodman, "Health effects of the London bicycle sharing system: health impact modelling study," BMJ, vol. 348, 2014.

[15] L. Zhang, J. Zhang, Z.-y. Duan, and D. Bryde, "Sustainable bike-sharing systems: characteristics and commonalities across cases in urban China," Journal of Cleaner Production, vol. 97, no. 15, pp. 124-133, 2015.

[16] R. B. Noland, M. J. Smart, and Z. Guo, "Bikeshare trip generation in New York City," Transportation Research Part A: Policy and Practice, vol. 94, pp. 164-181, 2016.

[17] W. El-Assi, M. Salah Mahmoud, and K. Nurul Habib, "Effects of built environment and weather on bike sharing demand: a station level analysis of commercial bike sharing in Toronto," Transportation, vol. 44, no. 3, pp. 589-613, 2017.

[18] Y. j. Ji, X. W. Ma, M. J. He, and Y. F. Yuan, "Comparison of usage regularity and its determinants between docked and 
dockless bike-sharing systems: a case study in Nanjing, China," Journal of Cleaner Production, vol. 255, pp. 1-11, 2020.

[19] T. Kayhan and T. Mohammad, "Hub network design for integrated Bike-and-Ride services: a competitive approach to reducing automobile dependence," Journal of Cleaner Production, vol. 248, Article ID 119247, 2020.

[20] Y. J. Cao and D. Shen, "Contribution of shared bikes to carbon dioxide emission reduction and the economy in Beijing," Sustainable Cities and Society, vol. 51, Article ID 101749, 2019.

[21] E. Fishman, S. Haworth, N. Washington, and N. Haworth, "Bike share's impact on car use: evidence from the United States, Great Britain, and Australia," Transportation Research Part D: Transport and Environment, vol. 31, pp. 13-20, 2014.

[22] F. Daniel, L. Gauvin, and Y. Kestens, "The potential modal shift and health benefits of implementing a public bicycle share program in Montreal," International Journal of Behavioural Nutrition and Physical Activity, vol. 10, 2013.

[23] Y. Tang, H. Pan, and Q. Shen, "Bike-sharing systems in Beijing, Shanghai, and Hangzhou and their impact on travel behaviour," in Proceedings of the 90th Transportation Research Board Annual Meeting, TRID, Washington, DC, USA, November 2011.

[24] S. Shaheen and E. Martin, Unraveling the Modal Impacts of Bikesharing, University of California Transportation Center Working Papers, Berkeley, CA, USA, 2015.

[25] E. Fishman, S. Washington, and N. Haworth, "Understanding the fear of bicycle riding in Australia," Journal of the Australasian College of Road Safety, vol. 23, no. 3, pp. 19-27, 2012.

[26] E. Fishman, S. Washington, and N. Haworth, "Bike share: a synthesis of the literature," Transport Reviews, vol. 33, no. 2, pp. 148-165, 2013.

[27] S. Shaheen, E. Martin, A. P. Cohen, and R. Finson, Public Bikesharing in North America: Early Operator and User Understanding, Mineta Transportation Institute, San Jose, CA, USA, 2012.

[28] L. D. A. Consulting, Capital Bikeshare 2013 Member Survey Report, http://capitalbikeshare.com/assets/pdf/CABI2013SurveyReport.pdf, Capital Bikeshare, Washington, DC, USA, 2013, http://capitalbikeshare.com/assets/pdf/CABI2013SurveyReport.pdf.

[29] K. M. Parker, J. Rice, J. Ruley, A. Spriggs, and C. Johnson, "Effect of bike lane infrastructure improvements on ridership in one New orleans neighborhood," Annals of Behavioral Medicine, vol. 45, no. S1, pp. 101-107, 2013.

[30] K. L. Wang and Y. J. Chen, "Joint analysis of the impacts of built environment on bikeshare station capacity and trip attractions," Journal of Transport Geography, vol. 82, Article ID 102603, 2020.

[31] The New York City Council, "Five-year plans for city streets, sidewalks, and pedestrian spaces," 2019, https://legistar. council.nyc.gov/LegislationDetail.aspx?

$\mathrm{ID}=3954291 \&$ GUID=D37BA0B0-9AB6-434B-A82E-

E49A7895A1A4\&Options $=\&$ Search $=$.

[32] J. X. Cao, C. C. Xue, M. Y. Jian, and X. R. Yao, "Research on the station location problem for public bicycle systems under dynamic demand," Computers \& Industrial Engineering, vol. 127, pp. 971-980, 2018.

[33] R. A. Rixey, "Station-level forecasting of bikesharing ridership," Transportation Research Record: Journal of the Transportation Research Board, vol. 2387, no. 1, pp. 46-55, 2013.

[34] H. M. Grow, B. E. Saelens, J. Kerr, N. H. Durant, G. J. Norman, and J. F. Sallis, "Where are youth active? Roles of proximity, active transport, and built environment,"
Medicine \& Science in Sports \& Exercise, vol. 40, no. 12, pp. 2071-2079, 2008.

[35] J. Pucher, J. Dill, and S. Handy, "Infrastructure, programs, and policies to increase bicycling: an international review," Preventive Medicine, vol. 50, pp. S106-S125, 2010.

[36] A. Faghih-Imani, N. Eluru, A. M. El-Geneidy, M. Rabbat, and U. Haq, "How land-use and urban form impact bicycle flows: evidence from the bicycle-sharing system (BIXI) in Montreal," Journal of Transport Geography, vol. 41, pp. 306-314, 2014.

[37] D. Buck and R. Buehler, "Bike lanes and other determinants of capital bike share trips," in Proceedings of the 91st Annual Meeting of the Transportation Research Board, TRID, pp. 22-26, Washington, DC, USA, January 2012.

[38] E. Fishman, S. Washington, N. Haworth, and A. Watson, "Factors influencing bike share membership: an analysis of Melbourne and Brisbane," Transportation Research Part A: Policy and Practice, vol. 71, pp. 17-30, 2015.

[39] Y. Sun, A. Mobasheri, X. Hu, and W. Wang, "Investigating impacts of environmental factors on the cycling behavior of bicycle-sharing users," Sustainability, vol. 9, no. 6, p. 1060, 2017.

[40] Y. Zhang, D. Lin, and Z. Mi, "Electric fence planning for dockless bike-sharing services," Journal of Cleaner Production, vol. 206, pp. 383-393, 2019.

[41] J. Dill and T. Carr, "Bicycle Commuting and facilities in major U.S. cities: if you build them, commuters will use them," Transportation Research Record, vol. 1828, pp. 116-123, 2003.

[42] T. Gotschi and K. Mills, Active Transportation for America: The Case for Increased Federal Investment in Bicycling and Walking, Rails-to-Trails Conservancy, Washington, DC, USA, 2008.

[43] S. Shaheen, E. Martin, and A. Cohen, "Public bikesharing and modal shift behavior: a comparative study of early bikesharing systems in north America," International Journal of Transportation, vol. 1, no. 1, pp. 35-54, 2013.

[44] X. Ma, Y. Yuan, N. V. Oort, and S. Hoogendoorn, "Bike-sharing systems' impact on modal shift: a case study in delft, The Netherlands," Journal of Cleaner Production, vol. 259, Article ID 120846, 2020.

[45] X. Ma, R. Cao, and J. Wang, "Effects of psychological factors on modal shift from car to dockless bike sharing: a case study of Nanjing, China," International Journal of Environmental Research and Public Health, vol. 16, p. 3240, 2019.

[46] N. Barbour, Y. Zhang, and F. Mannering, "A statistical analysis of bike sharing usage and its potential as an auto-trip substitute," Journal of Transport \& Health, vol. 12, pp. 253-262, 2019.

[47] J. Bachand-Marleau, B. H. Y. Lee, and A. M. El-Geneidy, "Better understanding of factors influencing likelihood of using shared bicycle systems and frequency of use," Journal of the Transportation Research Board, vol. 2314, pp. 66-71, 2014.

[48] R. Stewart, "I want to ride my bicycle: the relationship between bicycle infrastructure and commuting by car in U.S. cities," Master thesis, Georgetown University, Washington, DC, USA, 2013.

[49] F. Ogilvie and A. Goodman, "Inequalities in usage of a public bicycle sharing scheme: socio-demographic predictors of uptake and usage of the London (UK) cycle hire scheme," Preventive Medicine, vol. 55, no. 1, pp. 40-45, 2012.

[50] J.-R. Lin and T.-H. Yang, "Strategic design of public bicycle sharing systems with service level constraints," Transportation Research Part E: Logistics and Transportation Review, vol. 47, no. 2, pp. 284-294, 2011. 
[51] E. Heinen, K. Maat, and B. van Wee, "The effect of work-related factors on the bicycle commute mode choice in The Netherlands," Transportation, vol. 40, no. 1, pp. 23-43, 2013.

[52] R. Cervero, O. L. Sarmiento, E. Jacoby, L. F. Gomez, and A. Neiman, "Influences of built environments on walking and cycling: lessons from bogotá," International Journal of Sustainable Transportation, vol. 3, no. 4, pp. 203-226, 2009.

[53] L. M. Braun, D. A. Rodriguez, T. Cole-Hunter et al., "Short-term planning and policy interventions to promote cycling in urban centers: findings from a commute mode choice analysis in Barcelona, Spain," Transportation Research Part A: Policy and Practice, vol. 89, pp. 164-183, 2016.

[54] C. Park and S. Y. Sohn, "An optimization approach for the placement of bicycle-sharing stations to reduce short car trips: an application to the city of Seoul," Transportation Research Part A Policy \& Practice, vol. 105, pp. 154-166, 2017.

[55] M. Yang, X. Liu, W. Wang, Z. Li, and J. Zhao, "Empirical analysis of a mode shift to using public bicycles to access the suburban metro: survey of Nanjing, China," Journal of Urban Planning and Development, vol. 142, no. 2, Article ID $05015011,2016$.

[56] S. Zhou and Y. Ni, "Effects of dockless bike on modal shift in metro commuting: a pilot study in Shanghai," in Proceedings of the 97th Transportation Research Board Annual Meeting, TRID, Washington, DC, USA, January 2018.

[57] Huhhot Municipal Bureau of Statistics, "Huhhot statistical yearbook, 2019," 2019, http://tjj.huhhot.gov.cn/nj/2019nj/gb2. html.

[58] K. E. Train, Discrete Choice Methods with Simulation, Cambridge University Press, London, UK, 2009.

[59] G. Akar, N. Fischer, and M. Namgung, "Bicycling choice and gender case study: the Ohio State University," International Journal of Sustainable Transportation, vol. 7, no. 5, pp. 347-365, 2013.

[60] E. Heinen, B. van Wee, and K. Maat, "Commuting by bicycle: an overview of the literature," Transport Reviews, vol. 30, no. 1, pp. 59-96, 2010.

[61] E. Fishman, "Bikeshare: a review of recent literature," Transport Reviews, vol. 36, no. 1, pp. 92-113, 2016.

[62] S. Shaheen, E. Martin, N. Chan, A. Cohen, and M. Pogodzinski, Public Bikesharing in North America during a Period of Rapid Expansion: Understanding Business Models, Industry Trends and User Impacts, Mineta Transportation Institute, San Jose, CA, USA, 2014.

[63] D. A. Hensher, J. M. Rose, and W. H. Greene, "Combining RP and SP data: biases in using the nested logit "trick"-contrasts with flexible mixed logit incorporating panel and scale effects," Journal of Transport Geography, vol. 16, no. 2, pp. 126-133, 2008. 